\title{
A Case Study of Public Relations - Based on Haidilao's Successful Response to Emergencies
}

\author{
Jiaxuan $\mathrm{Xu}^{*}$ \\ Jiangnan University, Wuxi 214000, Jiangsu Province, China \\ *Corresponding author: Jiaxuan Xu, 13383578008@163.com
}

\begin{abstract}
This article analyzes Haidilao's successful response to emergencies and concludes that in the event of a public relations crisis, it is important for enterprises to emphasize on timeliness and have a quick response strategy, correctly identify and respond to questions raised by the public, as well as to make full use of the new media environment.
\end{abstract}

Keywords: Haidilao; Public; Media

Publication date: August 2021; Online publication: August 30, 2021

\section{Event background}

Public relations (PR) activities of enterprises are extremely important when there is a reputation crisis ${ }^{[1]}$. In 2017, Haidilao Hot Pot sparked an instant online backlash after a news report exposed the filthy hygiene of its kitchen.

At 10:55 a.m. on August 25, 2017, Legal Evening News published a report titled "Haidilao's Food Safety Issue" after a four-month undercover investigation. This aroused huge public opinion. Later, more than a dozen media such as ifeng.com, ynet.com, and Sina reposted this news one after another, accelerating the spread of Haidilao's hygiene crisis. Adverse online comments flooded in, causing the industry leader, Haidilao, to receive negative opinions from the public instantly.

\section{Solution}

After the emergence of the crisis, Haidilao successfully reversed the public opinion by issuing three announcements, thus heading off danger. The specific countermeasures are as follows: At 2:46 p.m. on August 25, within four hours after being exposed, Haidilao posted an apology letter on its official Weibo account. On the same day at 5:16 p.m., the second notice was issued in regard to the handling of the incident, reversing the public opinion. On August 27, Haidilao issued the third announcement to state its implementing rectification. In order to clarify the actual timeline of the corresponding measures and the changes in the public opinion, this paper summarized them in Figure 1 (information that have been circled in red are the specific measures done by Haidilao). 


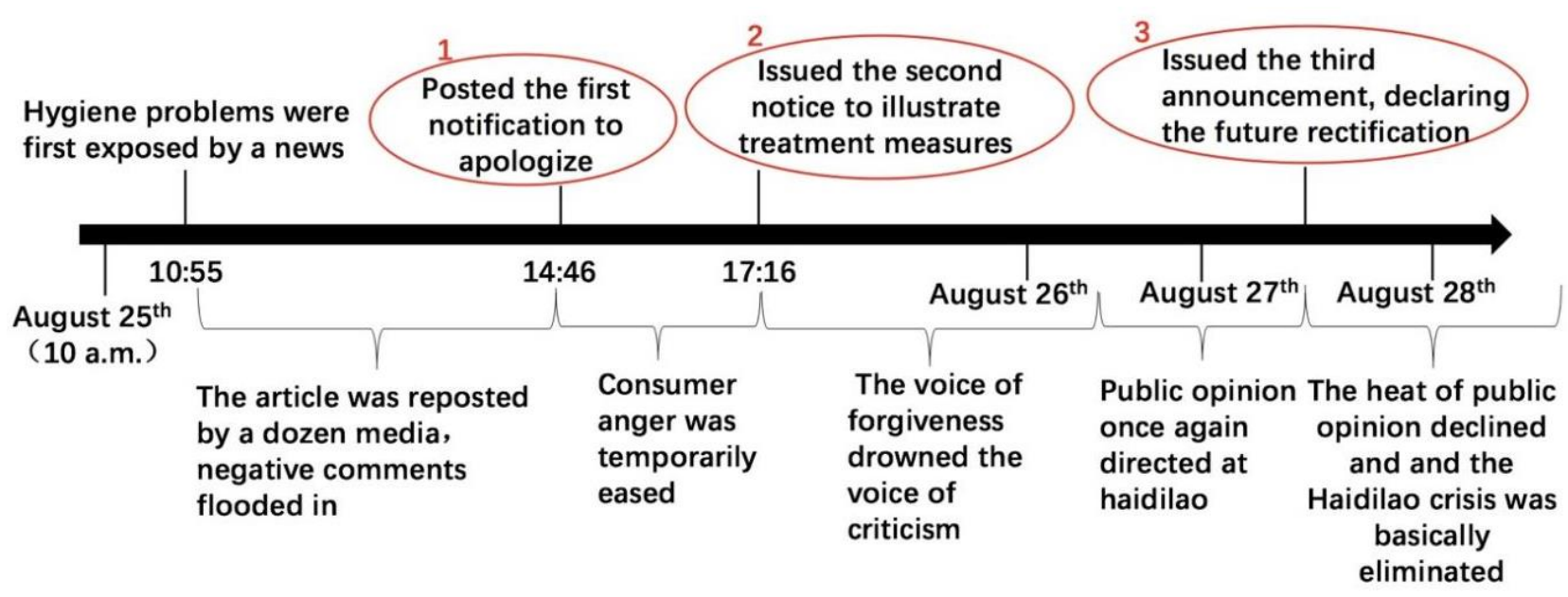

Figure 1. Timeline of Haidilao's response and the changes in public opinion

\section{Program evaluation}

\subsection{Preparation}

At this stage, the paper will mainly analyze from the aspect of program content. The three circulars that was issued addressed the objectives spelled out for the target publics to a large extent, manifesting a full display of sincerity and determination to correct the public opinion with high efficiency. To be specific, the first letter of apology was unequivocal in sincerity in admitting the mistake and in determination to take responsibility, thus achieving the goal of appeasing the consumers initially. The second announcement that was released revealed seven measures in dealing with the hygiene problem in response to the public's handling of the matter. The third rectification statement stated that all kitchen operations across the country would be visualized and would actively accept social supervision, sublimating a level on the basis of the second one and proving the implementation of the rectification to consumers again.

\subsection{Implementation}

In terms of distribution, the target groups are largely covered by the media that Haidilao have chosen for information delivery. This lies in the fact that as of August 28, 2017, the total number of reposts of those three circulars, posted on Sina Weibo by the official media account, "Haidilao," reached 18,122, with 18,103 likes and 12,492 comments, involving over 150 million cyber citizens. In terms of placement, Haidilao's PR materials were presented accurately and attractively by involving several influential media. Articles ${ }^{[2]}$ such as "Haidilao turned over a new leaf. I'll go back" and "Admits mistakes, timely rectification, Haidilao sets a new example for the industry" were published by many media at that time, which expressed exactly what Haidilao wanted to convey to the public.

\subsection{Impact}

In terms of the effect of the public relations, the measures by Haidilao brought great changes in public attitudes. Before releasing the first announcement, negative terms such as "nausea," "internal organs," and "health problems" were the most highly searched keywords in regard to the expose of Haidilao's health incident on the internet. After the second notification was issued, there were significant changes in the views of the netizens toward Haidilao: trending search terms were replaced with positive ones, such as "responsible," "correct," and "exemplary."

However, in terms of sustainability, the results of this PR have a low repetition rate, which reflected in the fact that citizen's attitudes can be easily reversed at a later stage. After applauding Haidilao's superb 
crisis management, public attention gradually shifted back to its hygiene problem, leading to the change of several consumers from "forgive" to "do not forgive." The media also published a few negative articles at the later stage. For example, China Central Television (CCTV) News made a comment, "To tolerate Haidilao is to be cruel to the safety of one's tongue."

\section{Enlightenment}

Haidilao's food hygiene and safety incident is a typical case of a timely and proper emergency management of public relations crisis. Such speed, attitude, and measures are worth learning for all enterprises. In the event of a public relations crisis, enterprises should do the following:

(1) Emphasize on timeliness and have a quick response strategy.

In this era with new media, information spreads rapidly, thus the earlier the involved party acts in a crisis, the more the party is able to grasp the discourse power ${ }^{[3]}$. One of the decisive factors of Haidilao in managing and defusing the crisis was the speed of the response. In the face of the severe situation, Haidilao detected the problem in a short period of time and took practical steps. Within four hours after the incident, Haidilao made the first response with the purpose of apologizing, which was the most critical step in reversing the trend of public attitudes.

(2) Correctly identify and respond to questions raised by the public.

In this way, the effectiveness of the content in public relations programs can be improved. In the announcement statement, Haidilao responded directly to the main issue and appeased the dissatisfactions in the hearts of the target groups. It is worth mentioning that in the process of public relations, many enterprises fail to determine the pain points of the public, thus executing ineffective responses, which often greatly reduce their corporate image and even causing the inability to recover after setbacks. Therefore, the effectiveness of public relations is determined in terms of having a targeted response to public dissatisfaction. Enterprises should answer questions head-on and sincerely communicate with the public to improve the effectiveness of public relations programs.

(3) Make full use of the new media environment.

In a highly informationalized age, new media, with its characteristics of rapid transmission, wide transmission range, and strong interactivity, have become indispensable for enterprises to communicate. It is the new media environment that Haidilao used to spread information to the target groups. In fact, it is because of the information posted on its official microblog, it quickly became a hot search and gained numerous retweets, thus greatly improving the efficiency of information transmission. Therefore, making full use of the new media environment would determine whether the implementation stage of a program would be able to proceed smoothly.

\section{Disclosure statement}

The author declares that there is no conflict of interest.

\section{References}

[1] Chen YT, 2016, Research on Corporate Public Relations. The Scientific Herald, 000(007): 141-2.

[2] Zhang YL, Fan SJ, 2017, Haidilao "Kitchen Incident” Crisis PR Touched the Consumer which String?. Public Relations, 000(019): 56-9.

[3] Zhang LS, 2010, Humble Opinion on Public Relations and Enterprise Development. Operation Manager (3): 207. 